\title{
Laboratory recreation of the Draupner wave and the role of breaking in crossing seas
}

\author{
M. L. McAllister ${ }^{1}$, S. Draycott ${ }^{2}$, T. A. A. Adcock ${ }^{1}$, P. H. Taylor ${ }^{1,3}$ and \\ T. S. van den Bremer ${ }^{1, \dagger}$ \\ ${ }^{1}$ Department of Engineering Science, University of Oxford, Oxford OX1 3PJ, UK \\ ${ }^{2}$ School of Engineering, University of Edinburgh, Edinburgh EH9 3FB, UK \\ ${ }^{3}$ Faculty of Engineering and Mathematical Sciences, University of Western Australia, \\ Crawley WA 6009, Australia
}

(Received 11 May 2018; revised 30 August 2018; accepted 30 October 2018;

first published online 11 December 2018)

Freak or rogue waves are so called because of their unexpectedly large size relative to the population of smaller waves in which they occur. The $25.6 \mathrm{~m}$ high Draupner wave, observed in a sea state with a significant wave height of $12 \mathrm{~m}$, was one of the first confirmed field measurements of a freak wave. The physical mechanisms that give rise to freak waves such as the Draupner wave are still contentious. Through physical experiments carried out in a circular wave tank, we attempt to recreate the freak wave measured at the Draupner platform and gain an understanding of the directional conditions capable of supporting such a large and steep wave. Herein, we recreate the full scaled crest amplitude and profile of the Draupner wave, including bound set-up. We find that the onset and type of wave breaking play a significant role and differ significantly for crossing and non-crossing waves. Crucially, breaking becomes less crest-amplitude limiting for sufficiently large crossing angles and involves the formation of near-vertical jets. In our experiments, we were only able to reproduce the scaled crest and total wave height of the wave measured at the Draupner platform for conditions where two wave systems cross at a large angle.

Key words: surface gravity waves, wave breaking, waves/free-surface flows

\section{Introduction}

The Draupner wave, recorded in the North Sea on 1 January 1995 (Haver 2004), was one of the first verified measurements of a freak wave, making it a highly seminal observation of a rare natural phenomenon. In the time since, other extremely large freak waves such as the Andrea (Magnusson \& Donelan 2013) and the Killard (Flanagan et al. 2016) have also been recorded. However, the mechanism by which such waves occur is still an open question. Of the possible mechanisms (see Kharif \& Pelinovsky 2003; Dysthe \& Müller 2008; Onorato et al. 2013; Adcock \& Taylor 2014), the two general theories that prevail in the absence of specific environmental

$\dagger$ Email address for correspondence: ton.vandenbremer@eng.ox.ac.uk 
forcing are random dispersive focusing enhanced by weak bound-wave nonlinearity on the one hand and the modulational instability of waves trains in deep water on the other. The latter applies most strongly to sea states that are narrow banded in both frequency and direction and sufficiently deep (typically, $k d \gg 1.36$, where $k$ is the wavenumber and $d$ the water depth) (Janssen 2003; Onorato et al. 2009; Waseda, Kinoshita \& Tamura 2009; Fedele et al. 2016). Modulational instability has been observed in the real ocean (e.g. Tulin 1996). Studies based on observations such as the Draupner wave (Clauss \& Klein 2009; Adcock et al. 2011; Christou \& Ewans 2014; Fedele et al. 2016) suggest that dispersive focusing enhanced by bound-wave nonlinearity, particularly for crossing wave systems, could provide a sufficient explanation in some cases. It has also been shown that for certain angles, crossing seas may also enhance the occurrence of modulational instability (Onorato, Osborne \& Serio 2006; Toffoli et al. 2011b; Cavaleri et al. 2012). For the Draupner wave in a water depth $d=70 \mathrm{~m}$ and with a zero-crossing period $T_{z}=12.5 \mathrm{~s}$, the non-dimensional water depth $k d=1.6$ ( $k$ is the wavenumber) is probably not sufficiently above the limit of 1.36 for modulational stability to have played an important role (Cavaleri et al. 2016)

Beyond its overall wave height of $h=25.6 \mathrm{~m}$ (height abnormality index $h / H_{s}=$ 2.13, where $H_{s}$ is the significant wave height, defined as four times the standard deviation of the surface elevation) and crest height of $a=18.5 \mathrm{~m}$ (crest abnormality index $\left.a / H_{s}=1.55\right)$, the Draupner wave is exceptional in a number of other ways (see Janssen 2015; Cavaleri et al. 2016; van Groesen, Turnip \& Kurnia 2017, for a discussion of its likelihood). First, the wave group itself was accompanied by what is most probably a set-up of the wave-averaged free surface, whereas a set-down is expected in the absence of crossing (Walker et al. 2004). The wave-averaged free surface, represented spectrally by second-order difference waves, is the local mean surface elevation formed by temporal averaging over the rapidly varying waves that make up the slowly varying group. In the case of crossing wave systems, a set-down of the wave-averaged free surface typically observed underneath a wave group can turn into a set-up, enhancing the maximum crest amplitude. This can be theoretically predicted (Okihiro, Guza \& Seymour 1992; Herbers, Elgar \& Guza 1994; Toffoli, Onorato \& Monbaliu 2006; Christou et al. 2009) based on second-order interaction kernels (Hasselmann 1962; Sharma \& Dean 1981; Dalzell 1999; Forristall 2000). A set-up has been observed in field data (Walker et al. 2004; Toffoli et al. 2007; Santo et al. 2013) and recently in detailed laboratory experiments (McAllister et al. 2018). Second, when modelled numerically using a fully nonlinear potential flow model (Yan \& Ma 2010), a wave of comparable steepness could not be created without triggering breaking in non-crossing-sea states (Adcock et al. 2011). Third, the structural loads on the Draupner platform (Hansteen, Jostad \& Tjelta 2003) were much smaller than would be expected for such a large (non-crossing) wave (Adcock et al. 2011). All of these properties suggest that the Draupner wave occurred when two smaller waves systems crossed. Subsequent analysis using a higher-order spectral method performed on the Draupner, Andrea and Killard waves also supports this finding (Fedele et al. 2016).

Hindcast predictions of the local wave climate surrounding the Draupner event can give an indication of the presence of crossing wave systems. There have been a number of attempts to hindcast the sea state, including Adcock et al. (2011), Cavaleri et al. (2016) and Fedele et al. (2016). The former two studies do suggest a secondary wave system; Adcock et al. (2011) only found this when resolution of the model was increased above that used as standard in such simulations. The hindcasts in Fedele 
et al. (2016) do not indicate crossing, but this may be due to low resolution as stated by the authors. Haver (2004) described the meteorological conditions at the time as a combination of large winter depression and short duration 'Arctic bomb': a much smaller but more violent wind field with a significantly different mean direction. This is a very difficult scenario to hindcast accurately: the sea state is steep with all the source terms in the wind-wave model large and with conditions changing over a time scale of tens of minutes. Notwithstanding the difficulty of modelling this rapidly evolving sea state, hindcasts consistently provide evidence that suggests separate wind and swell systems were present at different angles (Adcock et al. 2011; Cavaleri et al. 2016).

Independent of the focussing mechanism (linear or nonlinear) that created it, perhaps the most important question is under which directional conditions a waveform as steep as was observed at Draupner can be created without crest-amplitude-limiting breaking. Although fully nonlinear simulations can provide guidance, such approaches have limited capability to predict breaking unequivocally (see Barthelemy et al. 2018, for a recent discussion of a unified kinematic breaking criterion). Detecting the occurrence of wave breaking in field measurements of the free surface is also non-trivial (Perlin, Choi \& Tian 2013). Albeit always at reduced scale, physical laboratory experiments have an important role to play. The most successful previous attempt to experimentally reproduce the Draupner wave under unidirectional conditions by Clauss \& Klein (2009) has not fully reproduced the steepness of the wave observed in the field nor the observed set-up.

Herein, we present a series of physical experiments carried out in the FloWave Ocean Energy Research Facility; this circular wave tank surrounded by 168 wavemakers allows for the creation of waves travelling in all directions. Using this capability, we recreate a wave of equal and greater steepness to the Draupner event with an equivalent surface elevation time series and demonstrate the directional conditions necessary for it to exist. In doing so, we also show that the breaking mechanism can be fundamentally altered in crossing seas: breaking no longer acts to limit amplitude in the same way, but results in upward, jet-like behaviour. We thus propose an additional fundamental process to be taken into account when seeking explanation of rogue waves in highly directional seas such as at Draupner: directional breaking for crossing seas.

This paper is laid out as follows. First, details of our experimental and analysis methods are given in $\S 2$. Results of our experiments are laid out in $\S 3$, addressing the effects of directional spreading and wave breaking. A direct comparison with previous experimental results by Clauss \& Klein (2009) is provided in $\S 3.4$. Finally, conclusions are drawn in $\S 4$.

\section{Methods}

\subsection{Experimental set-up}

Experiments were conducted in the FloWave Ocean Energy Research Facility (www.flowave.eng.ed.ac.uk), based at the University of Edinburgh, UK. The facility consists of a $25 \mathrm{~m}$ diameter circular wave basin, surrounded by 168 active-absorbing force-feedback wavemakers, with a water depth of $2 \mathrm{~m}$. This circular geometry enables the creation of waves in all directions, and thus facilitates the generation of crossing wave groups at arbitrary angles. A linear array of eight multiplexed resistance-type wave gauges were installed along the tank centreline ( $x$-axis) and sampled at $128 \mathrm{~Hz}$. All measurements presented are at the intended point of focus at the centre of the tank $(x=0, y=0)$, unless stated otherwise. 

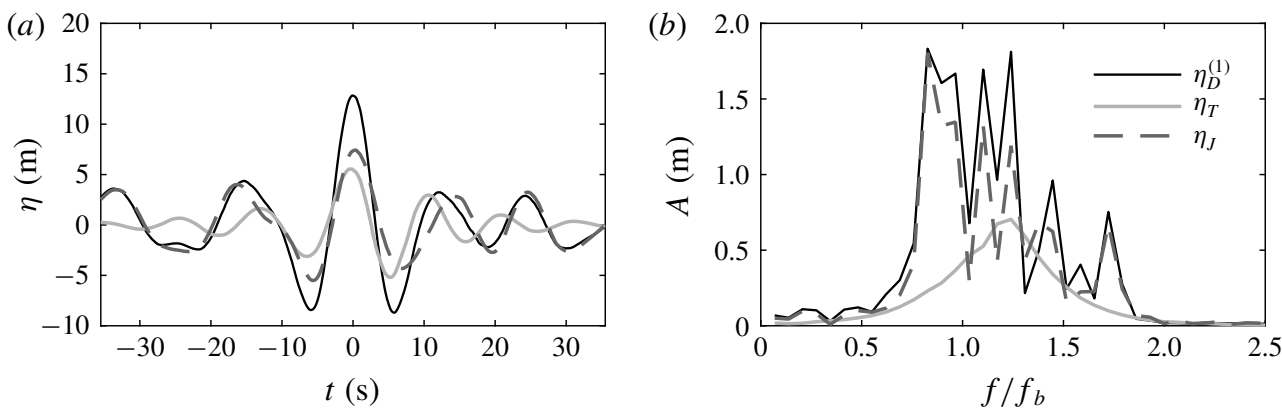

FIGURE 1. Decomposition of the Draupner event into two crossing systems, where the main wave train $\eta_{M}(t)$ (grey dashed lines), and the transverse waves $\eta_{T}(t)$ (grey solid lines) combine to give the linearised Draupner time series $\eta_{D}^{(1)}(t)=\eta_{M}(t)+\eta_{T}(t)$ (black lines). Panel $(a)$ shows the decomposition in the time domain, and $(b)$ shows the corresponding amplitude distributions in frequency. The amplitude distribution in frequency $A(f)$, shown on the $y$-axis of $(b)$, is obtained by taking the discrete Fourier transform of $\eta(t)$ in $(a)$.

\begin{tabular}{lcccccccc}
\hline & $\Delta \theta$ & $\sigma_{\theta}$ & $h_{d}(\mathrm{~m})$ & $h_{u}(\mathrm{~m})$ & $a(\mathrm{~m})$ & $a_{-}^{(2)}(\mathrm{m})$ & $k_{d} d$ & $k_{u} d$ \\
Expt. 1 & $0^{\circ}$ & $30^{\circ}$ & $24.2(23.7)$ & $23.5(24.0)$ & $16.6(17.2)$ & $-0.014(-0.046)$ & 1.68 & 1.85 \\
Expt. 2 & $60^{\circ}$ & $30^{\circ}$ & $23.9(24.3)$ & $23.9(25.5)$ & $18.0(18.4)$ & $0.069(0.050)$ & 1.76 & 1.87 \\
Expt. 3 & $120^{\circ}$ & $30^{\circ}$ & $25.4(25.5)$ & $24.5(25.7)$ & $17.9(18.9)$ & $0.27(0.31)$ & 1.76 & 1.89 \\
Draupner & - & - & 25.0 & 25.6 & 18.5 & 0.26 & 1.74 & 1.91
\end{tabular}

TABLE 1. Recreation of the Draupner wave for three crossing angles $\Delta \theta=0,60$ and $120^{\circ}$. Values given are measured at the intended point of focus $(x=0, y=0)$ with largest values measured at adjacent probes $(x= \pm 0.1, y=0 \mathrm{~m}$ at laboratory scale) given in brackets.

To match the water depth at the Draupner platform of $70 \mathrm{~m}$ and ensure similitude of wave kinematics, a Froude length scaling factor of 35 was implemented $(k d=1.7-1.9$, see table 1). A test duration of $16 \mathrm{~s}(94.7 \mathrm{~s}$ at field scale) was chosen to minimise the effects of tank reflections whilst allowing for sufficient time to reproduce the Draupner wave group (see appendix A).

\subsection{Input conditions}

In order to recreate a directional signal corresponding to the time series measured at Draupner (Haver 2004), assumptions need to be made, as directional information cannot be directly inferred from these measurements. We adopt the decomposition of the linearised Draupner time series into two crossing systems in Adcock et al. (2011), which is based on the observation of a transient bimodal peak in the spectrum measured immediately surrounding the large crest. Adcock et al. (2011) carried out an approximate linearisation of the free surface elevation measured at Draupner, first by high-pass filtering to remove second-order difference waves, then by minimising the skewness of the resulting signal to remove the effects of second-order sum waves. Then, the linearised spectrum was divided into two parts: the main wave train $\eta_{M}$, based on the assumption of an underlying Joint North Sea Wave Project (JONSWAP) (Hasselmann et al. 1973) spectrum, and a transient group $\eta_{\mathrm{T}}$. Together, these two parts combined to give the original linearised spectrum (see figure 1). We use this decomposition as input to the wavemakers. 
(a)

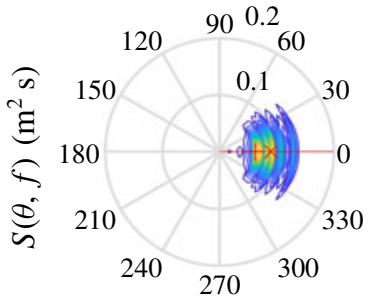

(b)

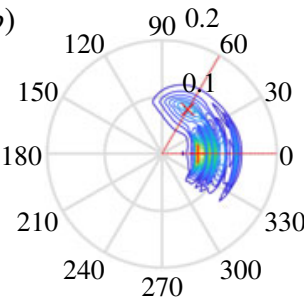

(c)

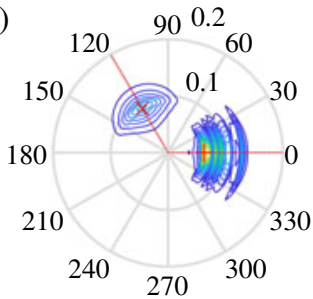

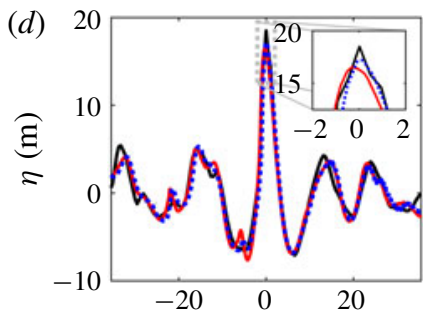
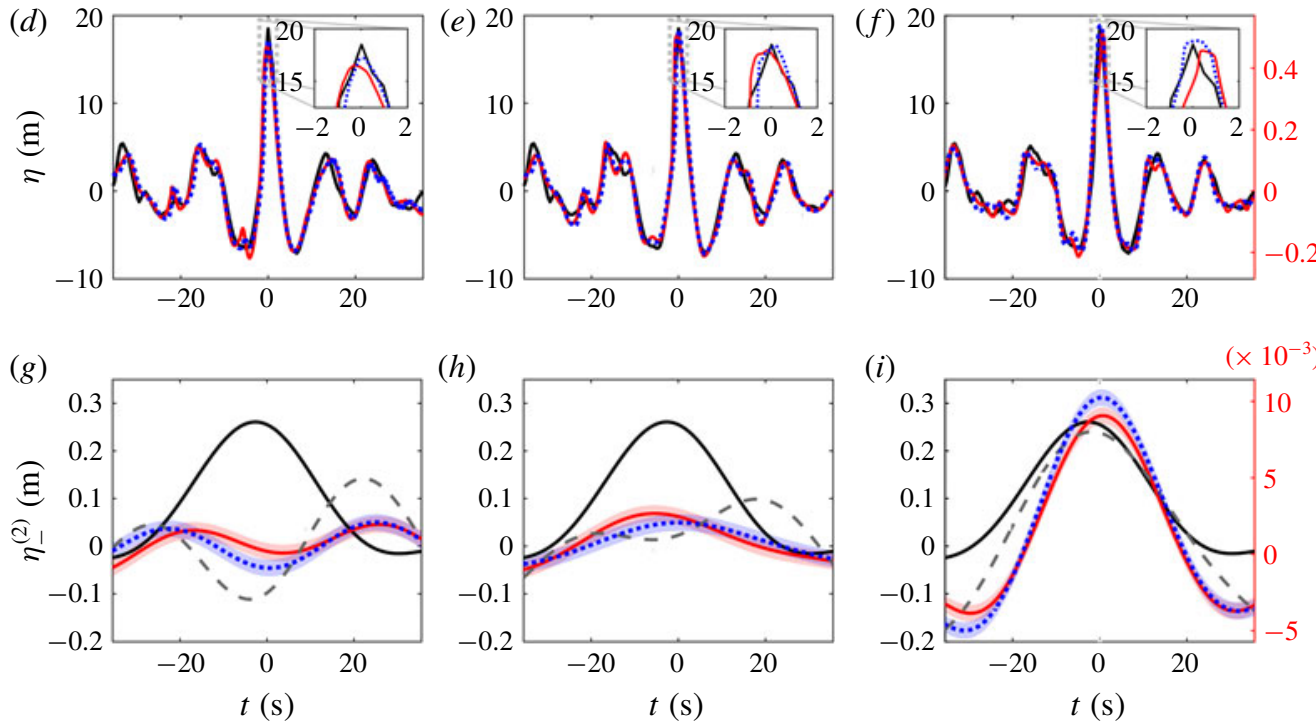

(h)

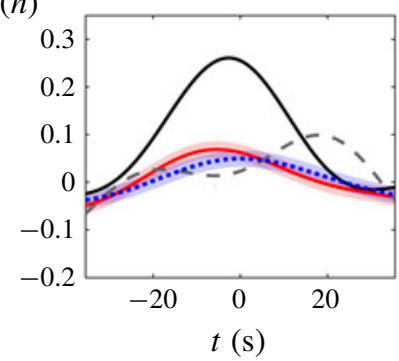

FIGURE 2. (Colour online) Recreation of the Draupner wave for three crossing angles $\Delta \theta=0^{\circ}, 60^{\circ}, 120^{\circ}$ and directional spreading $\sigma_{\theta}=30^{\circ}$ : polar plots of input directional spectra $S(\theta, f)(a-c)$, free surface elevation $\eta(t)(d-f)$ and second-order difference waves $\eta_{-}^{(2)}(t)(g-i)$. The black lines denote measurements made at the Draupner platform, the red lines our experimental measurements at the intended point of focus $(x=0, y=0)$ and the blue dotted lines our experimental measurements at an adjacent probe $(x= \pm 0.1, y=0 \mathrm{~m}$ at laboratory scale). The shaded areas in $(g-i)$ show estimated measurement errors, and the grey dashed lines theoretical predictions of $\eta_{-}^{(2)}(t)$. The left-hand axis shows field scale, and the right-hand axis laboratory scale (in red).

Both systems are also spread about their mean directions based on a wrappednormal amplitude distribution in $\theta$ with standard deviation $\sigma_{\theta}$. We set $\sigma_{\theta}=30^{\circ}$. Noting that our $\sigma_{\theta}$ corresponds to the standard deviation of the amplitude distribution, $\sigma_{\theta}=30^{\circ}$ corresponds to a standard deviation of $30 / \sqrt{2} \approx 21^{\circ}$ for the equivalent power spectrum, which is consistent with estimates in both Adcock et al. (2011) and Cavaleri et al. (2016). In all cases the main wave train $\left(\eta_{M}\right)$ has been generated with a mean direction of propagation along the tank's $x$-axis, with the mean direction of the transverse group $\left(\eta_{T}\right)$ altered to provide the desired crossing angle $\Delta \theta$. We set the crossing angle $\Delta \theta$ between the two systems to 0,60 , and $120^{\circ}$, illustrated in figure $2(a-c)$ and corresponding to experiments $1-3$ (see table 1 ). The case $\Delta \theta=0^{\circ}$ corresponds to a so-called 'following' sea state. 


\subsection{Iterative procedure}

To achieve the best recreation of the Draupner time series we adopt an iterative experimental approach. For each set of directional conditions, we iterate the components of the amplitude distribution (amplitude and phase) input to the wavemakers to achieve the target Draupner waveform at the point of intended focus at the centre of the tank $(x=0, y=0)$. The details of the procedure we adopt are mostly motivated by practical considerations. The decomposition above defines the relative amplitude $A_{T}\left(f_{n}\right) / A_{M}\left(f_{n}\right)$ and phase $\varphi_{T}\left(f_{n}\right)-\varphi_{M}\left(f_{n}\right)$ at each discrete frequency $f_{n}$ for the two systems. These relative amplitudes and phases are fixed throughout the iterative procedure, and hence the directional spreading and angle between the two systems is maintained. At each iteration, we applied corrections to the total input amplitude $A_{\text {input }}\left(f_{n}\right)$ and phase $\varphi_{\text {input }}\left(f_{n}\right)$ for each frequency in order to achieve the original Draupner measurement $A_{D}\left(f_{n}\right)$ and $\varphi_{D}\left(f_{n}\right)$ as the target. For each frequency component $f_{n}$, we computed the amplitude and phase inputs for iteration $j+1$ based on the observed amplitude $A_{\text {observed }, j}\left(f_{n}\right)$ and phase $\varphi_{\text {observed }, j}\left(f_{n}\right)$ at iteration $j$ :

$$
\begin{array}{r}
A_{\text {input }, j+1}\left(f_{n}\right)=\left[\frac{A_{D}\left(f_{n}\right)}{A_{\text {observed }, j}\left(f_{n}\right)}\right] A_{\text {input }, j}\left(f_{n}\right) \quad \text { and } \\
\varphi_{\text {input }, j+1}\left(f_{n}\right)=\varphi_{\text {input }, j}\left(f_{n}\right)+\beta\left[\varphi_{D}\left(f_{n}\right)-\varphi_{\text {observed }, j}\left(f_{n}\right)\right],
\end{array}
$$

where we use $\beta=1 / j$ as an effective way to achieve convergence. Typically, 7-8 iterations were required to achieve the optimal reproduction of the crest height and surrounding waveform (details of the iterations are given in appendix B).

\section{Results}

\subsection{Experimental recreation of the Draupner wave}

Figure $2(d-f)$ shows the achieved reconstruction of the Draupner wave for the three crossing angles $\Delta \theta=0,60$ and $120^{\circ}$. To compare, we present the experimental results at field scale using a Froude scaling, by scaling up length scales by a factor 35 (the ratio of water depths at Draupner of $70 \mathrm{~m}$ and in the laboratory of $2 \mathrm{~m}$ ) and time scales up by a factor $\sqrt{35}$. Where a larger wave crest was observed at either of two probes immediately adjacent to the intended point of focus $(x= \pm 0.1 \mathrm{~m}$, $y=0 \mathrm{~m}$ at laboratory scale, which corresponds to $\approx 1 \%$ of a wavelength), the free surface elevations measured there are also presented (blue dashed lines). In the following-sea state $\left(\Delta \theta=0^{\circ}\right.$, figure $\left.2 a, d\right)$, it was not possible to reproduce the total amplitude, as crest-amplitude-limiting breaking occurred at $a=17.2 \mathrm{~m}$ (relative to a target of $18.5 \mathrm{~m}$ ). When we increase the crossing angle to $60^{\circ}$ (figure $2 b, e$ ), better reproduction of the crest amplitude is observed (with a slight underproduction of $0.1 \mathrm{~m}$ ). Finally, for a crossing angle of $120^{\circ}$, we observe an $18.9 \mathrm{~m}$ wave crest, slightly larger than at Draupner (figure $2 c, f$ ). Table 1 details the achieved reconstruction of the Draupner wave, including the down- and up-crossing wave heights $h_{d}$ and $h_{u}$, the total crest height above still water $a$ and the magnitude of the second-order difference components $a_{-}^{(2)}$ discussed hereafter. In addition to reproducing scaled crest height, it is also necessary to reproduce steepness $k h / 2$ to correctly scale the waves. Table 2 compares the up- and down-crossing steepness of the waves produced in our experiments to measurements at Draupner. Only the waves produced for crossing angle $\Delta \theta=120^{\circ}$ achieve equivalent steepness. 


$\begin{array}{lccccc} & \Delta \theta & \sigma_{\theta} & k_{d} h_{d} / 2 & k_{u} h_{u} / 2 & \text { Observed breaking type } \\ \text { Expt. 1 } & 0^{\circ} & 30^{\circ} & 0.29(0.28) & 0.31(0.32) & \text { Plunging } \\ \text { Expt. 2 } & 60^{\circ} & 30^{\circ} & 0.30(0.32) & 0.32(0.34) & \text { Plunging }+ \text { upward jet } \\ \text { Expt. 3 } & 120^{\circ} & 30^{\circ} & 0.32(0.32) & 0.33(0.35) & \text { Upward jet } \\ \text { Draupner } & - & - & 0.31 & 0.35 & \text { Unknown }\end{array}$

TABLE 2. Achieved steepnesses and types of breaking observed for three crossing angles $\Delta \theta=0,60$ and $120^{\circ}$. Values given are measured at the intended point of focus $(x=$ $0, y=0)$ with the largest values measured at adjacent probes $(x= \pm 0.1, y=0 \mathrm{~m}$ at laboratory scale) given in brackets. Values of the wavenumber are calculated using the linear dispersion relationship $\omega^{2}=g k \tanh (k d)$ and based on individual up- and down-crossing wave periods.

\subsection{Second-order bound harmonics}

Underlying our laboratory reproduction of the maximum crest amplitude in the original Draupner time series before crest-amplitude-limiting wave breaking, at a crossing angle of $120^{\circ}$, is our assumed directional decomposition. Since the actual directional decomposition during Draupner cannot be directly inferred from available field measurements, any such decomposition will remain somewhat arbitrary. We can gain further confidence in our results by examining the frequency-difference components of the second-order bound waves. In order to extract the bound waves contained within our measurements, we repeat each experiment with a phase shift of $180^{\circ}$. By subtracting the out-of-phase tests, it is then possible to separate the second-order sum and difference bound waves after filtering (Baldock, Swan \& Taylor 1996; Fitzgerald et al. 2014; Mai et al. 2016; Zhao et al. 2017). Evidently, this technique cannot be applied to field measurements of the Draupner wave. Instead, we extract bound difference waves in the infra-gravity regime through low-pass filtering only (at a $0.5 f_{p}$ cutoff), making the assumption that in this range of frequencies bound-wave interactions dominate. Any free waves that exist in the infra-gravity range in our experiments will be removed by the phase inversion process.

In figure $2(g-i)$, we compare the second-order difference waves $\left(\eta_{-}^{(2)}\right)$ thus extracted from the Draupner time series (black lines) and our experiments (red and blue lines). Initially, when $\Delta \theta=0^{\circ}$, a small set-down is observed, which becomes positive when the crossing angle $\Delta \theta$ is increased to $60^{\circ}$. Finally, when $\Delta \theta=120^{\circ}$, a large set-up forms with a similar amplitude $(0.27 \mathrm{~m})$ to the set-up observed under the Draupner wave $(0.26 \mathrm{~m})$. The confidence bands around the red and blue lines correspond to \pm 2 standard deviations, resulting from measurement errors only (see appendix $\mathrm{C}$ ). At field scale, the confidence bands have a magnitude of $0.035 \mathrm{~m}$. From comparison between the maximum amplitude of the second-order difference waves at Draupner and in experiments, noting the confidence bands, we thus find good agreement only for large crossing angles (cf. figure $2 g-i$ ).

Although the widely used (Mai et al. 2016; Zhao et al. 2017; McAllister et al. 2018) method of harmonic extraction (Baldock et al. 1996; Fitzgerald et al. 2014) we use relies on a generalised Stokes expansion and is thus not affected by cubic interactions, it cannot be fully relied on in the event of wave breaking. In our experiments, wave breaking occurs at the crest and not at the corresponding $180^{\circ}$ phase-inverted trough. This may lead to overestimation of the vertical asymmetry of the wave group and hence of the second-order difference waves. Predictions 
(a)

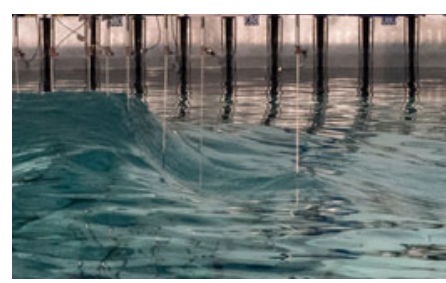

(d)

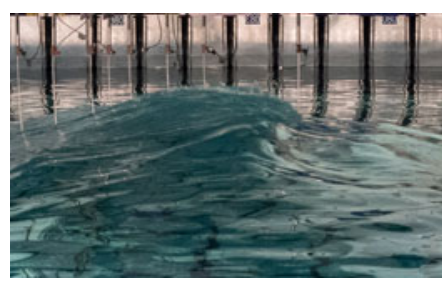

(b)

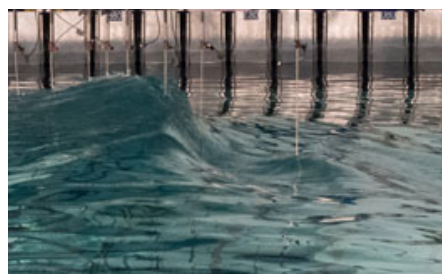

(e)

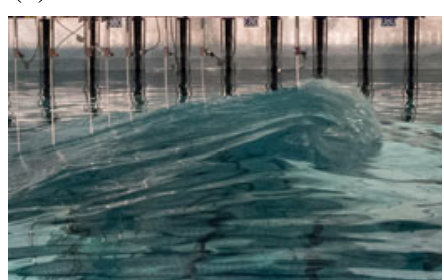

(c)

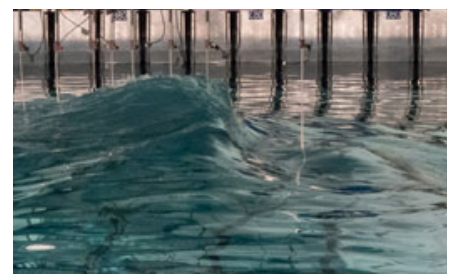

$(f)$

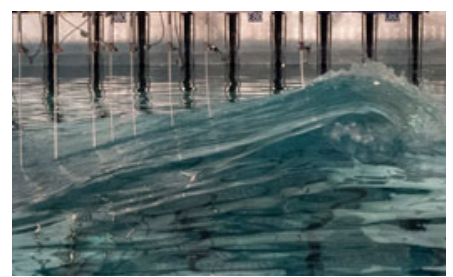

FIgURE 3. (Colour online) Still images of the free surface taken at intervals of $100 \mathrm{~ms}$ (0.6 s at field scale), showing the most successful reconstruction of the Draupner wave for $\Delta \theta=0^{\circ}$. Plunging breaking is observed, which provides an upper limit to wave crest amplitude under these following-sea conditions.

of the second-order difference waves based on second-order theory (Dalzell 1999), taking the linear part of the spectrum as an input, are also presented as the grey dashed lines in figure $2(g-i)$ (see appendix D for details of the calculation). The predicted second-order difference waves match our experimental observations well, giving confidence that we have correctly extracted the second-order bound long wave components.

\subsection{Wave breaking}

In the ocean, breaking provides the uppermost limit to wave steepness. In its most basic form, breaking is assumed to occur when the particle velocity at the crest exceeds the phase velocity, causing fluid in the crest to overtake the wave (Barthelemy et al. 2018). In deep to intermediate water depths, this can occur as a gentle local spilling motion or a violent jet that emanates horizontally from the crest and plunges into the forward face of the wave (Cokelet 1977). Figure 3(a-c) shows the onset of such a plunging breaker for following-sea conditions $\left(\Delta \theta=0^{\circ}\right)$, where, as the wave focuses, a near-vertical wall of water forms on the forward face of the wave, from which a plunging jet emerges (figure $3 d-f$ ). The measured time series at each probe are included in appendix E. In following-sea conditions, wave energy is spread about a single mean direction. As waves focus, large horizontal particle velocities are generated about the mean direction and waves may break. When the spread of energy about a single mean direction is large or when energy is spread over multiple directions (i.e. crossing waves), as opposed to focusing, the horizontal particle velocity of components normal to the mean direction under a wave crest begin to cancel out. This reduction in horizontal particle velocity affects the onset of wave breaking, as addressed explicitly in Latheef, Swan \& Spinneken (2017), who found that the maximum wave steepness for a given sea state was proportional to spreading width in following-sea conditions. Earlier, She, Greated \& Easson (1994), Nepf, Wu \& 
(a)

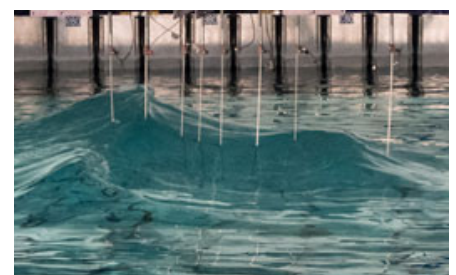

(d)

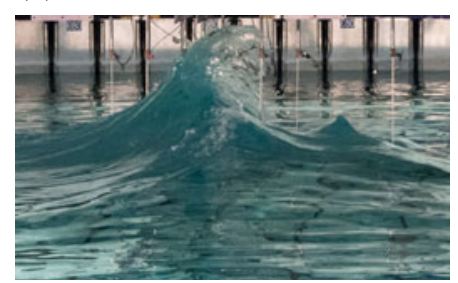

(b)

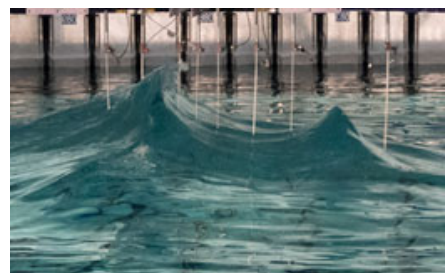

(e)

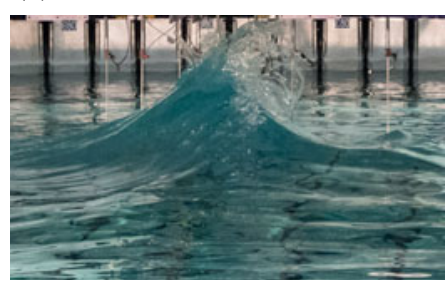

(c)

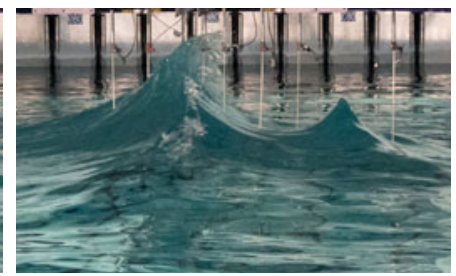

$(f)$

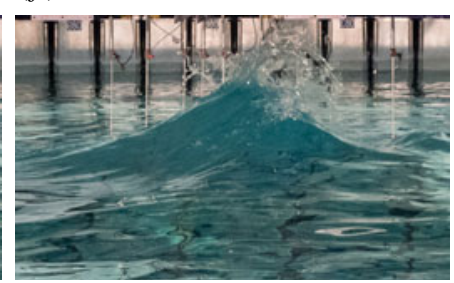

FIgURE 4. (Colour online) Still images of the free surface taken at intervals of $100 \mathrm{~ms}$ (0.6 s at field scale), showing the most successful reconstruction of the Draupner wave for $\Delta \theta=120^{\circ}$. Breaking is observed in from of an upward projected jet, which does not limit wave crest height under these crossing-sea conditions.

Chan (1998) and Babanin et al. (2011) have also observed that breaking waves may be larger and have steeper fronts as directional spreading is increased.

To examine breaking for crossing waves, we attempted recreation of the Draupner wave under following-sea conditions for increasing degrees of directional spreading $20^{\circ}, 30^{\circ}$ and $40^{\circ}$. In all three cases, as observed in figure 3 for $\sigma_{\theta}=30^{\circ}$, plunging breaking occurred, limiting the wave height that could be achieved. As the degree of spreading was increased, the maximum achievable wave height did increase, with respective crest heights of $16.57 \mathrm{~m}, 17.20 \mathrm{~m}$ and $17.22 \mathrm{~m}$. However, these tests still failed to reproduce the full crest of the Draupner wave by $1.9-1.3 \mathrm{~m}$. Increasing the degree of spreading further would potentially result in larger crest heights before breaking. In reality, steep following-sea states with such broad spreading are unlikely in extra-tropical storms.

Under crossing conditions, the breaking mechanism observed became fundamentally different. Figure 4 shows the onset of breaking when $\Delta \theta=120^{\circ}$. As the crossing waves combine, a jet forms that propels the water upwards. In this case, much of the horizontal motion is cancelled out at the point of focus and this results in a partial standing wave. Typical plunging-type breaking is not observed. The formation of vertical jets on standing waves, which has parallels with wave impact on walls (Boccotti et al. 1993; Peregrine 2003), has been examined by a number of authors (Longuet-Higgins 1983; Zeff et al. 2000; Longuet-Higgins 2001; Longuet-Higgins \& Dommermuth 2001). Its occurrence is significant for two reasons. First, this form of wave breaking can be associated with extremely large fluid accelerations of the order of $10-100 \times g$ (Longuet-Higgins 2001; Longuet-Higgins \& Dommermuth 2001). Second, this breaking mechanism does not directly limit the achievable wave height. In figure 5 , the onset of breaking is shown for $\Delta \theta=60^{\circ}$. Here, as the waves combine, breaking occurs along the confluence of the two crests. A mixture of horizontal and vertical motion is observed in a combination of the effects observed in figures 3 $\left(\Delta \theta=0^{\circ}\right)$ and $4\left(\Delta \theta=120^{\circ}\right)$. The spray that can be observed in figures 4 and 5 , 
(a)

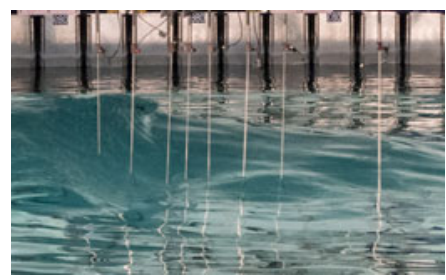

(d)

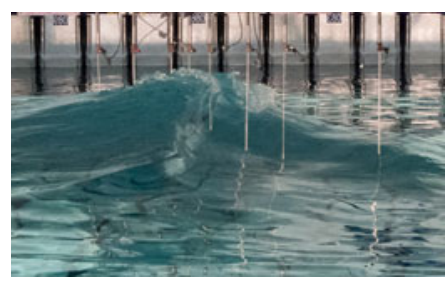

(b)

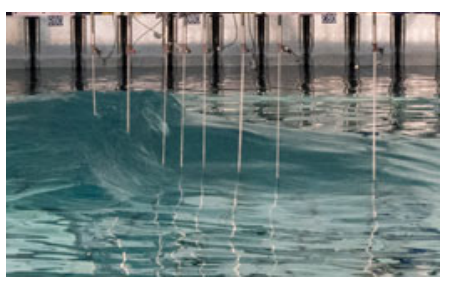

(e)

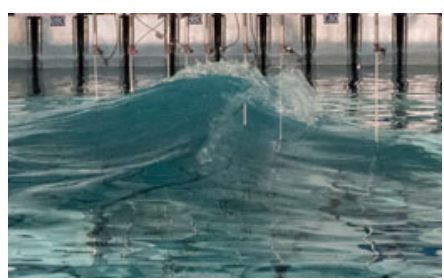

(c)

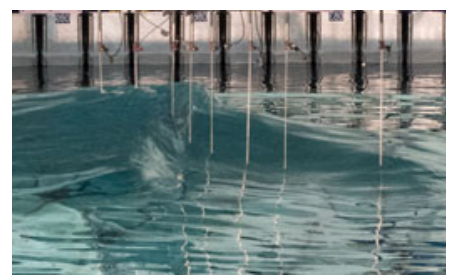

(f)

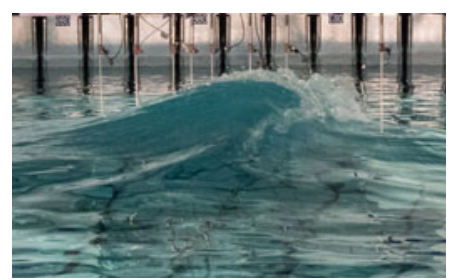

FIgURE 5. (Colour online) Still images of the free surface taken at intervals of $100 \mathrm{~ms}$ (0.6 s at field scale), showing the most successful reconstruction of the Draupner wave for $\Delta \theta=60^{\circ}$. Breaking is observed along the confluence of the crossing waves producing a jet with both horizontal (plunging) and jet-like upwards motion.

occurs in the foreground (in front of the gauges) and thus will not affect the maximum surface elevation measured by the gauges.

Local wave steepness is a common indicator used to predict the onset of wave breaking for Eulerian measurements. A maximum steepness of $k h / 2=0.44$ is often used (Michell 1893), which is based on the limiting steepness of a regular Stokes wave in deep water (Stokes 1847). Plunging breaking waves generated by dispersive focusing have been produced in experiments (Tian, Perlin \& Choi 2008) at steepnesses as low as $k h / 2=0.28$. For irregular waves the width of the underlying spectrum has a significant effect on wave breaking steepness (Rapp \& Melville 1990), and, in general, geometric criteria vary significantly from study to study (Perlin et al. 2013), perhaps illustrating the inadequacy of such overly simplified criteria. Based on observations, Wu \& Yao (2004) proposed the following relationship for limiting wave steepness (on a water depth of approximately $k d=1.3$ and for unidirectional waves):

$$
k h / 2=0.44 e^{3.0 v^{2}-3.9 v},
$$

where $v=\sqrt{m_{2} m_{0} / m_{1}^{2}-1}$ is the spectral bandwidth with $m_{n}$ representing the $n$th spectral moment taken over the interval $0.5-1.5 f_{p}$, where $f_{p}$ is the peak frequency. Using (3.1) to predict a maximum steepness based on the bandwidth of our spectrum, we obtain $k h / 2=0.22$. This relationship is based on unidirectional experiments, which will break at lower steepness. Nevertheless, we use this regression to provide a qualitative description of how the onset of breaking may be affected by bandwidth in our experiments. It serves as a lower bound for our directionally spread experiments. Other geometric criteria, such as crest-front steepness and horizontal asymmetry, may also be used to predict the onset of breaking (e.g. Perlin et al. 2013). A disadvantage of using geometric criteria based on temporal measurements is the need to assume a dispersion relationship, which can lead to variations in the estimated parameters as large as $50 \%$ (Yao \& Wu 2006). Although perhaps more accurate (see Barthelemy 


\begin{tabular}{lccccccccc}
\hline & $\Delta \theta$ & $\sigma_{\theta}$ & $h_{d}(\mathrm{~m})$ & $h_{u}(\mathrm{~m})$ & $a(\mathrm{~m})$ & $a_{-}^{(2)}(\mathrm{m})$ & $k_{d} h_{d} / 2$ & $k_{u} h_{u} / 2$ & $v$ \\
Expt. 3 & $120^{\circ}$ & $30^{\circ}$ & $25.4(25.5)$ & $24.5(25.7)$ & $17.9(18.9)$ & $0.27(0.31)$ & $0.32(0.32)$ & $0.33(0.35)$ & 0.21 \\
CK09 & $0^{\circ}$ & $0^{\circ}$ & 23.38 & 26.64 & 18.32 & -0.45 & 0.25 & 0.31 & 0.18 \\
Draupner & - & - & 25.0 & 25.6 & 18.5 & 0.26 & 0.31 & 0.35 & 0.21
\end{tabular}

TABLE 3. Comparison of our experimental reproduction (Expt. 3), the experimental reproduction of CK09 and the field measurements at the Draupner platform. Values given are measured at the intended point of focus $(x=0, y=0)$ with largest values measured at adjacent probes $(x= \pm 0.1, y=0 \mathrm{~m}$ at laboratory scale) given in brackets.

et al. 2018), dynamic and kinematic criteria require accurate measurements of surface velocities, which are non-trivial to obtain experimentally (e.g. Saket et al. 2017). The approximate local steepness of the waves created in our experiments is presented in table 2. For all cases, the steepness of our waves lies between 0.22 and 0.44 .

\subsection{Comparison with Clauss \& Klein (2009)}

Previously, Clauss \& Klein (2009) (CK09) have set out to reproduce the Draupner wave under unidirectional conditions in a $110 \mathrm{~m}$ long seakeeping basin. The scaled wave height $h$ and amplitude $a$ are reproduced well in CK09, despite being slightly smaller than measurements made at the Draupner platform with the exception of upcrossing wave height $h_{u}$, which is $1.1 \mathrm{~m}$ larger (see table 3). However, the actual waveform shows less good agreement with measurements at Draupner, as reflected by the lower $r^{2}$ values for CK09 compared to our experiments (see figure 6(a,b); $r^{2}$ values are calculated over time window presented). As evident from figure $6(a, b)$, the period of the wave produced in CK09 is longer than that observed at Draupner, as also evident from the spectra in figure $6(e, f)$. This gives the wave a different shape and ultimately reduces its steepness (see table 3 ). In the case of single Eulerian measurements, both wave height and period need to be matched in order to achieve the correct steepness and thus scaling of the wave. Furthermore, the waves in CK09 do not show a set-up but a considerable set-down of amplitude $-0.45 \mathrm{~m}$, which is expected for unidirectional waves (figure $6 c, d$ ).

The steepness of the waves in CK09 is comparable to the steepness at which our experiments for following, yet directionally spread, conditions displayed crestamplitude-limiting breaking (our Expt. 1). This difference in the onset of crestamplitude-limiting breaking may be explained by looking at the spectra of the waves in both sets of experiments. Considering the spectra for each set of experiments in figure $6(e, f)$ (here the spectral window is set to match the duration of our experiments), the results of CK09 are more narrow banded and have a lower spectral bandwidth parameter $v$ (see table 3), meaning they will break at a higher steepness following the regression of $\mathrm{Wu} \&$ Yao (2004) given in (3.1), which parametrises how the steepness at which breaking occurs is inversely proportional to spectral bandwidth. In Clauss \& Klein (2011) a breather-type wave with larger height and somewhat similar profile to the Draupner wave is also produced; such waves may also have very narrow underlying spectra, and waves generated through modulational instability have also been shown to break at higher steepness (Perlin et al. 2013). Hence, it may be possible to achieve waves of comparable steepness under unidirectional conditions using nonlinear focusing. 
(a) Expt. 3 $\Delta \theta=120^{\circ}, \sigma_{\theta}=30^{\circ}$
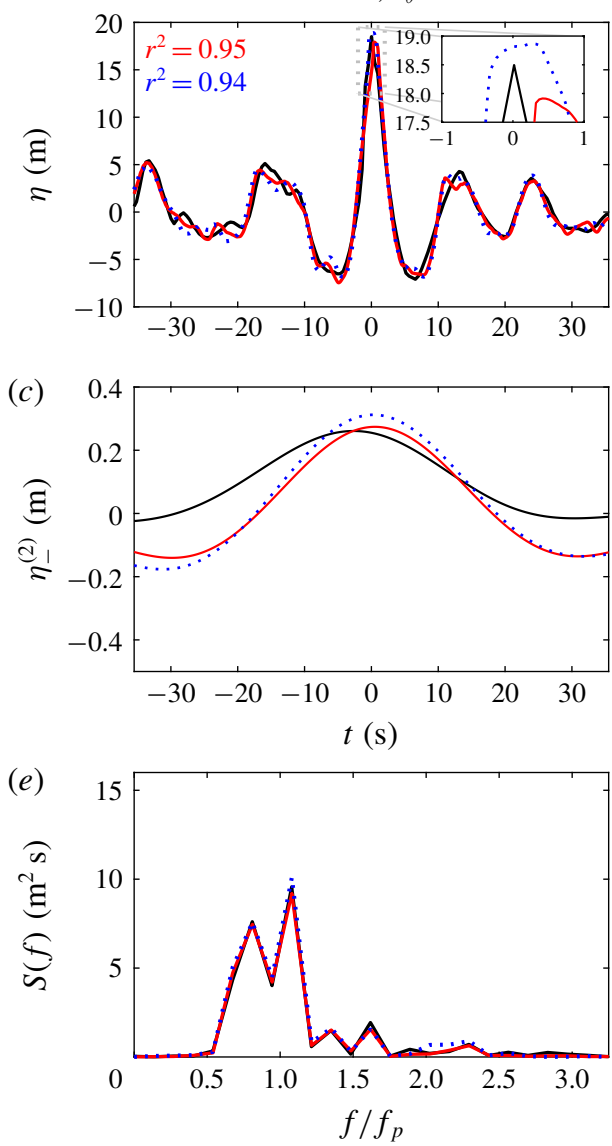

(b)

Clauss \& Klein (2009) $\Delta \theta=0^{\circ}, \sigma_{\theta}=0^{\circ}$

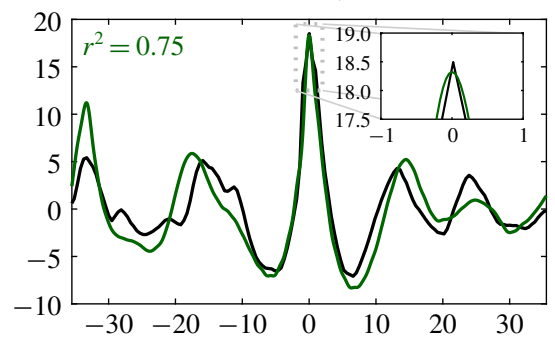

(d)

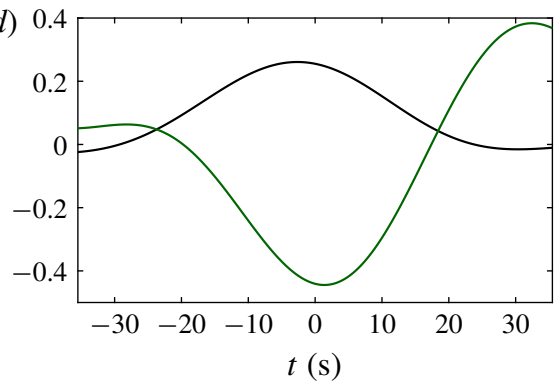

(f)

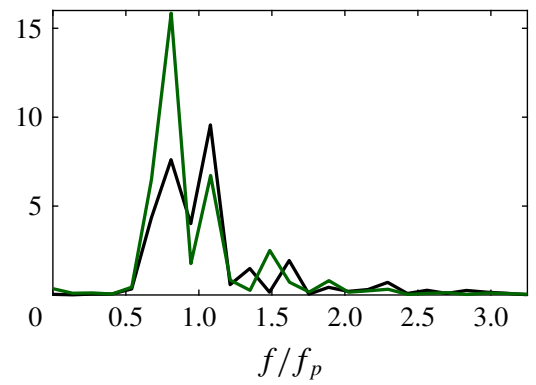

FIgURE 6. (Colour online) Comparison of our experimental reproduction, the experimental reproduction of CK09 and field measurements at the Draupner platform. The column on the left shows our Expt. 3 with red lines corresponding to measurements at the intended point of focus $(x=0, y=0)$ and blue dotted lines measurements at an adjacent probe $(x= \pm 0.1, y=0 \mathrm{~m}$ at laboratory scale). The column on the right shows the experimental results of CK09 (green lines). The black lines denote measurements made at the Draupner platform. Panels $(a, b)$ show the measured signals, $(c, d)$ second-order difference waves $\eta_{-}^{(2)}(t)$ and $(e, f)$ spectra of the free surface elevation.

\section{Conclusions}

The experimental results presented herein provide physical evidence that a wave of the same and greater steepness than the Draupner wave can arise as a result of crossing at large angles (between 60 and $120^{\circ}$ ). The presence of a set-up in the second-order difference waves, observed in both measurements made at the Draupner platform and in our experiments, further supports the hypothesis of Adcock et al. (2011) and Cavaleri et al. (2016) that crossing conditions created the Draupner wave. The set-down we observe under following-sea conditions provides confidence that the set-up measured at the Draupner platform was in fact probably a result of crossing waves and not an artefact of wave breaking. 


\subsection{The crossing angle}

Evidently, complete confidence in the directional distribution of energy underlying the historical wave Draupner wave cannot be attained. We have found that a crossing angle between 60 and $120^{\circ}$ is needed to reproduce the wave form, full crest amplitude and set-up of the wave-averaged free surface. Our finding is consistent with the hindcast results in Adcock et al. (2011), who find a crossing angle of approximately $80^{\circ}$, but probably somewhat higher than the more recent hindcasts by Cavaleri et al. (2016), who suggest a main peak with two low-frequency lobes at angles of $20^{\circ}$ above and $60^{\circ}$ below the wind-generated peak. The hindcasts in Fedele et al. (2016) do not indicate crossing, but these authors indicate the need for a higher resolution hindcast. We emphasise the difficulty of accurately predicting the directional distribution for crossing seas in hindcasts, especially in rapidly evolving sea states.

\subsection{Confidence in the field record}

The results presented herein compare measurements made at the Draupner platform during a severe North Sea storm to experiments carried out in a wave tank. These two environments differ in several ways. Our measurements were recorded using wave gauges, whereas the Draupner wave was measured with a downward pointing laser. Optical devices react differently to the presence of spray (see Toffoli et al. 2011a; Magnusson \& Donelan 2013). Therefore, although here we have assumed the Draupner measurement to be correct, it should be associated with a level of uncertainty. Magnusson \& Donelan (2013) have used the backscatter intensity of four measurements of the 2007 Andrea wave to confirm the reliability of this measurement and demonstrate the likely absence of spray of foam from the highest crest itself. For the Draupner wave, such a detailed examination of the (single) laser measurement has not been undertaken. We have found a difference between the maximum crest amplitudes we can achieve for following and crossing-sea conditions of 1.3-1.7 m at field scale. A measurement error of this magnitude in the 1995 field record is unlikely for a green-water wave but is not inconceivable for a breaking wave. Some assurance of the fidelity of this measurement can be gained from anecdotal reports of damage to equipment below deck level consistent with the measurement (Haver 2004) and, more importantly, from the set-up of the wave-averaged free surface. High wind speeds and surface currents, not accounted for in our experiments, may have also influenced the formation of the Draupner wave. Such conditions may also affect the formation of near-vertical jets observed in our experiments. In this study, we show that the Draupner wave could not have occurred for following-sea conditions in the absence of such external forcing.

\subsection{The role of wave breaking}

Wave breaking plays a key role in these experiments, and, as predicted by numerical modelling (Adcock et al. 2011), limits the maximum achievable wave height under following-sea conditions. In crossing conditions, the mechanism of breaking changes fundamentally; we observe the formation of near-vertical jets of green water. For our experiments this mechanism does not limit wave height in the same manner as plunging breaking. This behaviour was also observed for waves of reduced steepness. These observations are of significance to the design of offshore structures, in particular to ships and other floating bodies, where the impact of green water on deck can be catastrophic. Prior to the onset of breaking, the free surface likely behaves as in an 

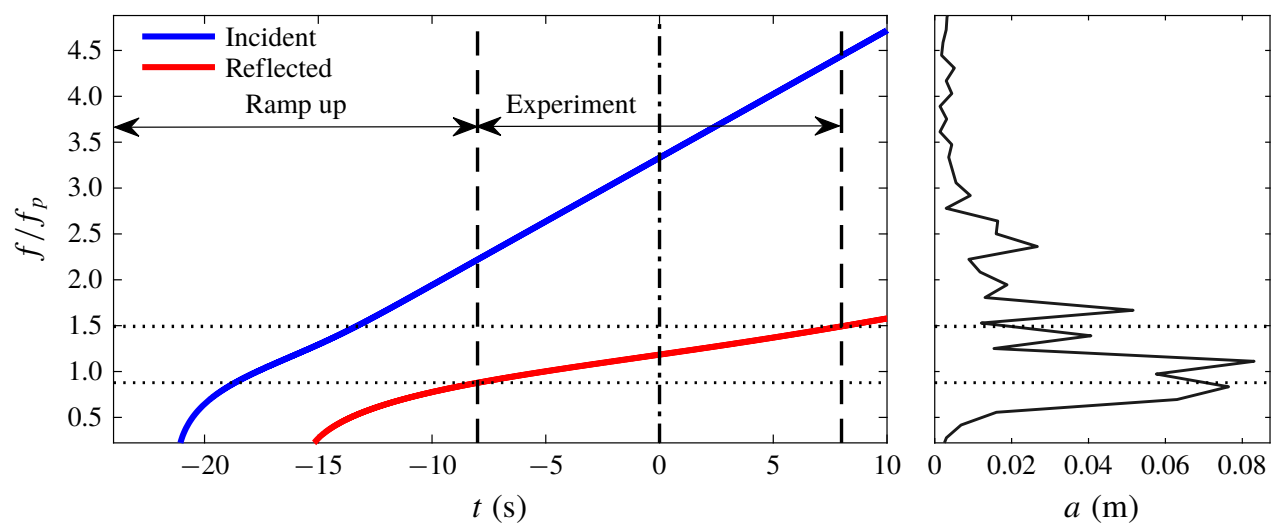

FIgURE 7. (Colour online) Arrival times of incident (blue line) and reflected waves (red line) at the intended point of focus at the centre of the tank $(x=0, y=0)$ as a function of frequency. For reference the input amplitude distribution in frequency is shown on the right.

irrotational potential flow. The jet that forms at the onset of breaking will ultimately be subject to viscous and capillary effects and may thus not be follow the same scaling laws between laboratory and field scales. In the formation of vertical jets, the distinction between the wave crest and the jet is perhaps less clear than for a plunging breaker, thus making it more difficult to assess the scalability of these results. A new body of empirical research should address wave breaking in crossing-sea conditions to fully understand these results, and to complement the established literature on breaking in directionally spread following seas.

\section{Acknowledgements}

The authors would like to thank Dr D. Noble for taking the photographs in figures 3-5 and Dr J. Steynor and Dr T. Davey at the FloWave Ocean Energy Research Facility (FloWave) for their help planning and carrying out the experiments. The FloWave facility was funded by the UK's Engineering and Physical Sciences Research Council under grant EP/I02932X/1. TSvdB was supported by a Royal Academy of Engineering Research Fellowship. The authors wish to thank Dr S. Haver, then at Statoil and now at Stavanger University, for making the Draupner surface elevation data widely available to the research community. Finally, the authors would also like to thank Dr M. Klein and Professor G. Clauss of TU Berlin for sharing their experimental results.

\section{Appendix A. Reflections}

To define the test duration and focus time, it was necessary to consider the propagation and resulting arrival times of both the incident and reflected wave systems. It is desired to ensure all key wave components have arrived to the measurement location, yet reflections are kept at a minimum. In an attempt to optimise this, a total test duration of $32 \mathrm{~s}$ was chosen (test scale), consisting of a $16 \mathrm{~s}$ ramp up period followed by the $16 \mathrm{~s}$ duration experiment. Figure 7 illustrates the expected arrival times of the incident and reflected frequency components, assuming linear dispersion. The duration of our measurements is indicated by the vertical dashed lines $(-8 \mathrm{~s}$ to 

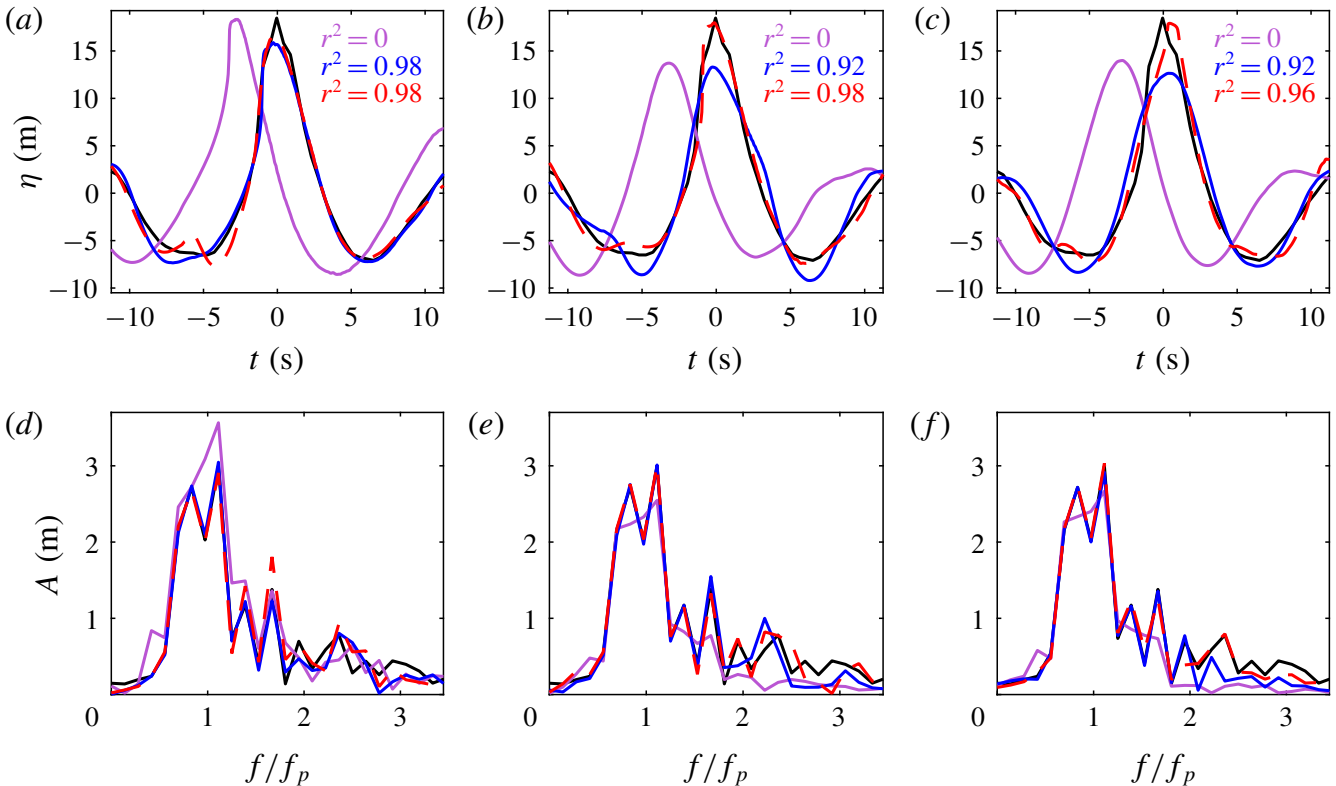

FIGURE 8. (Colour online) Iterative recreation of the Draupner wave for three crossing angles $\Delta \theta=0,60,120^{\circ}$ : free surface elevation $\eta(t)(a-c)$, and corresponding amplitude distributions in frequency $(d-f)$. The black lines denote measurements made at the Draupner platform, the red dashed lines our final experimental measurements at the intended point of focus $(x=0, y=0)$ and the first and fourth iterations are shown by the purple and blue lines, respectively.

$8 \mathrm{~s}$ ), with the Draupner wave crest occurring at $t=0$, as indicated by the dot-dashed line. Importantly, at $t=0$ all incident waves of frequency below $3 f_{p}$ have had sufficient time to arrive at the centre of the tank and can contribute to the recreation of the Draupner crest. At the start of the experiments, reflected wave frequencies below $0.8 f_{p}$ are present at the measurement location, with higher-frequency components arriving during the measurement period. Although this creates a non-stationary wave field and limits the ability to perform frequency domain reflection analysis, this experimental design limits the total influence of reflections significantly and thus improves the Draupner wave recreation.

From previous studies on the FloWave tank (Draycott et al. 2016), along with knowledge of $f_{p}$ and steepness of the Draupner input spectrum, it is expected that amplitude based reflection coefficients $\left(A_{r} / A_{i}\right)$ will be less than $10 \%$. At $t=0$, where only frequency components below $f_{p}$ are influencing the measurement, the effective overall influence of reflections is expected to be less than $5 \%$ by amplitude.

\section{Appendix B. Iterative procedure}

Figure 8 illustrates the iterative process for the results presented in figure 2 and table 1. Figure $8(a-c)$ shows the free surface elevation for consecutive iterations for the three crossing angles considered, whilst $(d-f)$ show the corresponding amplitude distributions in frequency. All the cases converge well upon the target free surface elevation with $r^{2}$ values greater than 0.95 . In the following-sea state $\left(\Delta \theta=0^{\circ}\right.$, figure $8 a$ ), the first iteration produces a wave which is of similar crest height 
to measurements at Draupner and larger than subsequent iterations. It is evident from figure $8(d)$, however, that the generated amplitude distribution does not agree well with the target. In addition, the period of this wave is also longer giving the wave down- and up-crossing steepnesses of $k_{d} h_{d} / 2=0.26$ and $k_{u} h_{u} / 2=0.29$, respectively. Subsequent iterations, although smaller, are steeper and thus represent a more accurate recreation of the Draupner waveform. Assessing the amplitude distributions (figure $8 d-f$ ), it is clear that frequencies of above approximately $2 f_{p}$ are not as well reproduced as the lower frequencies. At these higher frequencies, achieving the desired focusing can be problematic as small errors in wavemaker inputs or motions correspond to large errors in phase for these relatively short waves. However, as these waves are small in amplitude, this does not result in a significant underproduction of the desired waveform as seen in $(a-c)$.

\section{Appendix C. Measurement error}

To estimate the measurement uncertainty, the error associated with wave gauge calibration is calculated. The gauges were calibrated daily by positioning them at known heights in still water and fitting a linear relationship to the resulting measured voltage. The calibration error is taken as two times the standard deviation of the difference in predicted and known values of height. At test scale this represented an absolute error of $\pm 0.5 \mathrm{~mm}$, which corresponds to $\pm 0.0175 \mathrm{~m}$ at field scale. Noting the difference between the maximum crest amplitudes in our results is $1.3-1.7 \mathrm{~m}$ at field scale, these results are unlikely to be significantly affected by laboratory measurement error.

\section{Appendix D. Second-order calculations}

With knowledge of the linear free waves it is possible to predict the resulting second-order bound waves. If the linear free surface elevation is considered as a double summation of $N_{\omega}$ discrete components travelling in $N_{\theta}$ discrete directions, then

$$
\eta^{(1)}=\sum_{n=1}^{N_{\omega}} \sum_{i=1}^{N_{\omega}} a_{n, i} \cos \left(\varphi_{n, i}\right),
$$

where each discrete wave component has amplitude $a_{n, i}$ and phase $\varphi_{n, i}$, then the resulting second-order difference terms are given by the quadruple sum (Dalzell 1999)

$$
\eta_{-}^{(2)}=\sum_{n=1}^{N_{\omega}} \sum_{m=1}^{N_{\omega}} \sum_{i=1}^{N_{\theta}} \sum_{j=1}^{N_{\theta}} B^{-} a_{n, i} a_{m, j} \cos \left(\varphi_{n, i}-\varphi_{m, j}\right),
$$

where we take expressions for the second-order interaction kernels from $B^{-}$from Dalzell (1999). Second-order calculations are performed using (D2), based on the input linear free surface elevation and spreading distribution for each test.

\section{Appendix E. Measured time series}

Figure 9 shows the measured time series of the free surface elevation at the different probes along the $x$-axis for the three experiments (1-3), thus illustrating the spatial and temporal evolution around focus. It should be noted that gauges are located along the $x$-axis and thus only along the mean direction of propagation for $\Delta \theta=0^{\circ}$. It 

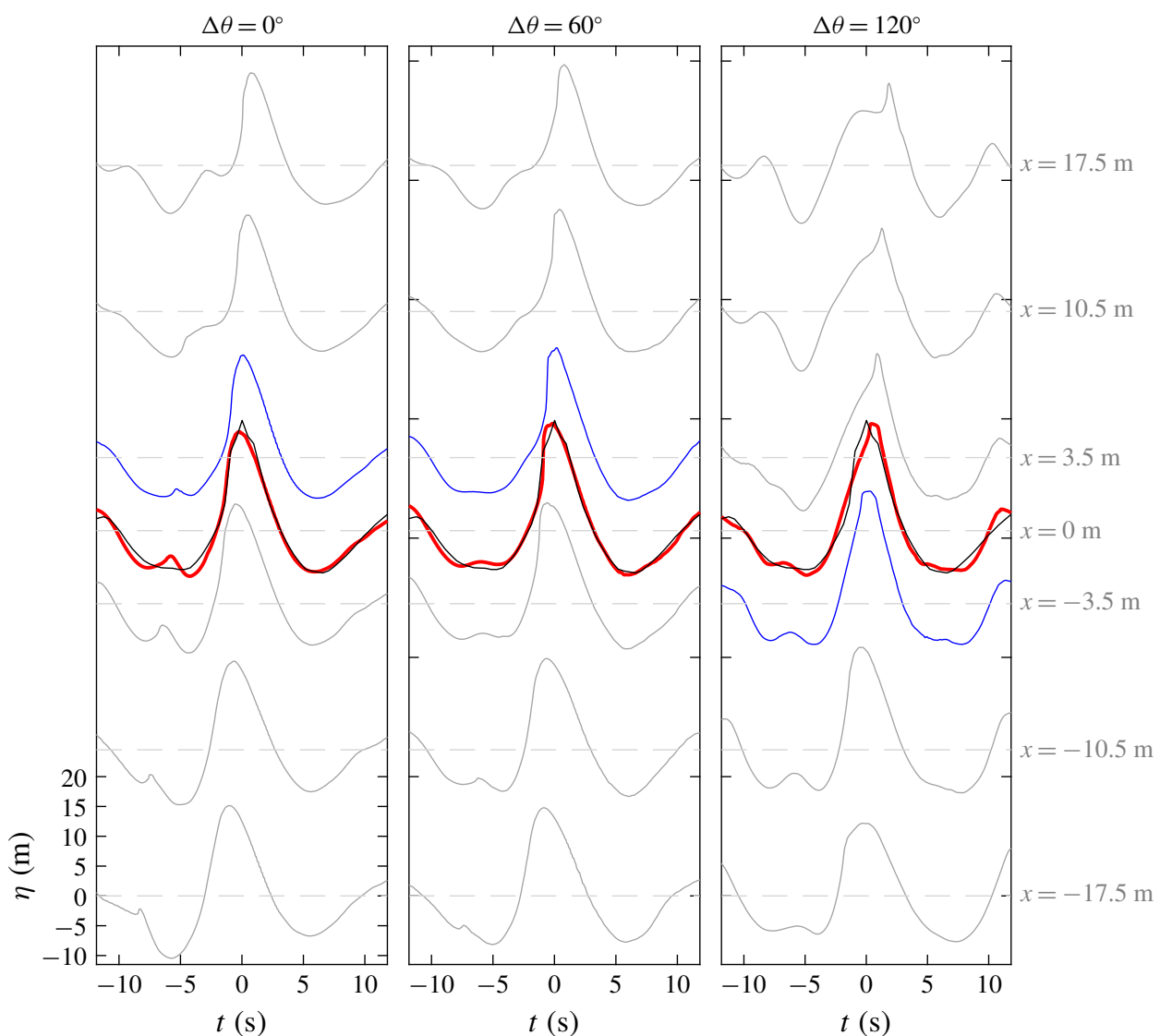

FIGURE 9. (Colour online) Measured time series of the free surface elevation at the different gauges along the $x$-axis for the three experiments (1-3). The horizontal dashed lines represent $z=0$, the black lines denote measurements made at the Draupner platform, the red lines our experimental measurements at the intended point of focus $(x=0, y=0)$ and the blue dotted lines our experimental measurements at an adjacent probe $(x= \pm 0.1$, $y=0 \mathrm{~m}$ at laboratory scale). The values of $t, x$ and $\eta$ are at full scale.

is evident from this figure that the main wave is more localised in space for large crossing angles. The sharp spike observed for large $x$ at $\Delta \theta=120^{\circ}$ likely corresponds to the formation of a jet and will be explored in more detail in future work.

\section{REFERENCES}

Adcock, T. A. A. \& TAYlor, P. H. 2014 The physics of anomalous ('rogue') ocean waves. Rep. Prog. Phys. 465, 3361-3381.

Adcock, T. A. A., Taylor, P. H., Yan, S., Ma, Q. W. \& Janssen, P. A. E. M. 2011 Did the Draupner wave occur in a crossing sea? Proc. R. Soc. Lond. A 467, 3004-3021.

Babanin, A. V., Waseda, T., Kinoshita, T. \& Toffoli, A. 2011 Wave breaking in directional field. J. Phys. Oceanogr. 41, 145-156.

BALdock, T. E., Swan, C. \& TAYLOR, P. H. 1996 A laboratory study of nonlinear surface waves on water. Phil. Trans. R. Soc. Lond. A 354, 649-676. 
Barthelemy, X., Banner, M. L., Peirson, W. L., Fedele, F., Allis, M. \& Dias, F. 2018 On a unified breaking onset threshold for gravity waves in deep and intermediate depth water. J. Fluid Mech. 841, 463-488.

Boccotti, P., Barbaro, G., Fiamma, V., Mannino, L. \& Rotta, A. 1993 An experiment at sea on the reflection of the wind waves. Ocean Engng 20, 493-507.

Cavaleri, L., Barbariol, L. F., Benetazzo, A., Bertotti, L., Bidlot, J. R., Janssen, P. A. E. M. \& WEDI, N. 2016 The Draupner wave: a fresh look and the emerging view. J. Geophys. Res. Oceans 128, 6061-6075.

Cavaleri, L., Bertotti, L., Torrisi, L., Bitner-Gregersen, E., Serio, M. \& Onorato, M. 2012 Rogue waves in crossing seas: The Louis Majesty accident. J. Geophys. Res. 117 (C11), C00J10.

Christou, M. \& Ewans, K. 2014 Field measurements of rogue water waves. J. Phys. Oceanogr. 44, 2317-2335.

Christou, M., Tromans, P., Vanderschuren, L. \& Ewans, K. 2009 Second-order crest statistics of realistic sea states. In Proc. of the 11th Int. Workshop on Wave Hindcasting and Forecasting, Halifax, Canada, pp. 18-23. Available at: http://www.waveworkshop.org.

Clauss, G. F. \& Klein, M. 2009 The New Year wave: spatial evolution of an extreme sea state. J. Offshore Mech. Arctic Engng 131, 041001.

Clauss, G. F. \& Klein, M. 2011 The new year wave in a seakeeping basin: generation, propagation, kinematics and dynamics. Ocean Engng 38, 1624-1639.

CoKelet, E. D. 1977 Breaking waves. Nature 267, 769-774.

Dalzell, J. F. 1999 A note on finite depth second-order wave-wave interactions. App. Ocean Res. 21, 105-111.

Draycott, S., Davey, T., Ingram, D. M., Day, A. \& Johanning, L. 2016 The SPAIR method: isolating incident and reflected directional wave spectra in multidirectional wave basins. Coast. Engng 114, 265-283.

Dysthe, K. B., Müller, H. E. \& Krogstad, P. 2008 Oceanic rogue waves. Annu. Rev. Fluid Mech. 40, 287-310.

Fedele, F., Brennan, J., De León, S. P., Dudley, J. \& Dias, F. 2016 Real world ocean rogue waves explained without the modulational instability. Sci. Rep. 6, 27715.

Fitzgerald, C. J., Taylor, P. H., Eatock Taylor, R., Grice, J. \& Zang, J. 2014 Phase manipulation and the harmonic components of ringing forces on a surface-piercing column. Proc. R. Soc. Lond. A 470, 20130847.

Flanagan, J. D., Dias, F., Terray, E., Strong, B.\& Dudley, J. 2016 Extreme water waves off the west coast of Ireland: analysis of ADCP measurements. In The 26th International Ocean and Polar Engineering Conference, p. ISOPE-I-16-589. International Society of Offshore and Polar Engineers.

Forristall, G. Z. 2000 Wave crest distributions: Observations and second-order theory. J. Phys. Oceanogr. 30, 1931-1943.

van Groesen, E., Turnip, P. \& Kurnia, R. 2017 High waves in Draupner seas part 1: numerical simulations and characterization of the seas. J. Ocean Engng Mar. Energy 3, 20160159.

Hansteen, O. E., Jostad, H. P. \& TJelta, T. I. 2003 Observed platform response to a 'monster' wave. In Field Measurements in Geomechanics, Oslo, Norway, pp. 15-18. A. A. Balkema.

HasselmanN, K. 1962 On the non-linear energy transfer in a gravity-wave spectrum. Part 1. General theory. J. Fluid Mech. 12, 481-500.

HasselmanN, K. et al. 1973 Measurements of wind-wave growth and swell decay during the Joint North Sea Wave Project (JONSWAP). In Ergänzungsheft, pp. 8-12. Deutches Hydrographisches Institut.

HAVER, S. 2004 A possible freak wave event measured at the Draupner jacket January 11995 . In Rogue Waves Workshop, pp. 1-8. Brest.

Herbers, T. H. C., Elgar, S. \& GuZA, R. T. 1994 Infragravity-frequency (0.005-0.05 Hz) motions on the shelf. Part I. Forced waves. J. Phys. Oceanogr. 24, 917-927.

Janssen, P. A. E. M. 2003 Nonlinear four-wave interactions and freak waves. J. Phys. Oceanogr. 33, 863-884.

Janssen, P. A. E. M. 2015 How rare is the Draupner Wave Event? ECMWF Tech. Memo. 775. European Centre for Medium-Range Weather Forecasts. 
Kharif, C. \& Pelinovsky, E. 2003 Physical mechanisms of the rogue wave phenomenon. Eur. J. Mech. (B/Fluids) 22, 603-634.

LAtheef, M., Swan, C. \& Spinneken, J. 2017 A laboratory study of nonlinear changes in the directionality of extreme seas. Proc. R. Soc. Lond. A 473, 20160290.

Longuet-Higgins, M. S. 1983 Bubbles, breaking waves and hyperbolic jets at a free surface. J. Fluid Mech. 127, 103-121.

Longuet-Higgins, M. S. 2001 Vertical jets from standing waves. Proc. R. Soc. Lond. A 457, 495-510.

Longuet-Higgins, M. S. \& Dommermuth, D. G. 2001 Vertical jets from standing waves II. Proc. R. Soc. Lond. A 457, 2137-2149.

Magnusson, A. K. \& Donelan, M. A. 2013 The Andrea wave characteristics of a measured North Sea rogue wave. J. Offshore Mech. Arctic Engng 135, 031108.

Mai, T., Greaves, D. M., Raby, A. C. \& TaYlor, P. H. 2016 Physical modelling of wave scattering around fixed FPSO-shaped bodies. App. Ocean Res. 61, 115-129.

McAllister, M. L., Adcock, T. A. A., TAYlor, P. H. \& VAn den Bremer, T. S. 2018 The set-down and set-up of directionally spread and crossing surface gravity wave groups. J. Fluid Mech. 835, 131-169.

Michell, J. H. 1893 The highest waves in water. Lond. Edinb. Dublin Phil. Mag. J. Sci. 36, 430-437.

NEPF, H. M., WU, C. H. \& CHAN, E. S. 1998 A comparison of two-and three-dimensional wave breaking. J. Phys. Oceanogr. 28, 1496-1510.

Okiniro, M., GuzA, R. T. \& Seymour, R. J. 1992 Bound infra-gravity waves. J. Geophys. Res. 97, 453-469.

Onorato, M., Osborne, A. R. \& Serio, M. 2006 Modulational instability in crossing sea states: a possible mechanism for the formation of freak waves. Phys. Rev. Lett. 96, 014503.

Onorato, M., Residori, S., Bortolozzo, U., Montina, A. \& Arecchi, F. T. 2013 Rogue waves and their generating mechanisms in different physical contexts. Phys. Rep. 528, 47-89.

Onorato, M., Waseda, T., Toffoli, A., Cavaleri, L., Gramstad, O., Janssen, P. A. E. M., Kinoshita, T., Monbaliu, J., Mori, N. A. R., Osborne, A. R., Serio, M., Stansberg, C. T., Tamura, H. \& Trulsen, K. 2009 Statistical properties of directional ocean waves: the role of the modulational instability in the formation of extreme events. Phys. Rev. Lett. 102, 114502.

Peregrine, D. H. 2003 Water-wave impact on walls. Annu. Rev. Fluid Mech. 35, 23-43.

Perlin, M., Choi, W. \& Tian, Z. 2013 Breaking waves in deep and intermediate waters. Annu. Rev. Fluid Mech. 45, 115-145.

RAPP, R. J. \& Melville, W. K. 1990 Laboratory measurements of deep-water breaking waves. Phil. Trans. R. Soc. Lond. A 331, 735-800.

Saket, A., Peirson, W. L., Banner, M. L., Barthelemy, X. \& Allis, M. J. 2017 On the threshold for wave breaking of two-dimensional deep water wave groups in the absence and presence of wind. J. Fluid Mech. 811, 642-658.

Santo, H., Taylor, P. H., Eatock Taylor, R. \& Choo, Y. S. 2013 Average properties of the largest waves in Hurricane Camille. J. Offshore Mech. Arctic Engng 135, 011602.

Sharma, J. N. \& DeAn, R. G. 1981 Second-order directional seas and associated wave forces. Soc. Petrol. Engng J. 21, 129-140.

She, K., Greated, C. A. \& Easson, W. J. 1994 Experimental study of three-dimensional wave breaking. ASCE J. Waterway Port Coastal Ocean Engng 120, 20-36.

Stokes, G. G. 1847 On the theory of oscillatory waves. Trans. Camb. Phil. Soc. 8, 441-455.

Tian, Z., Perlin, M. \& ChOI, W. 2008 Evaluation of a deep-water wave breaking criterion. Phys. Fluids 20, 066604.

Toffoli, A., Babanin, A. V., Donelan, M. A., Haus, B. K. \& Jeong, D. $2011 a$ Estimating sea spray volume with a laser altimeter. J. Atmos. Ocean. Tech. 28, 1177-1183.

Toffoli, A., Bitner-Gregersen, E. M., Osborne, A. R., Serio, M., Monbaliu, J. \& ONORATO, M. $2011 b$ Extreme waves in random crossing seas: laboratory experiments and numerical simulations. Geophys. Res. Lett. 38, L06605. 
Toffoli, A., Monbaliu, J., Onorato, M., Osborne, A. R., Babanin, A. V. \& BitneR-GREgersen, E. M. 2007 Second-order theory and setup in surface gravity waves: a comparison with experimental data. J. Phys. Oceanogr. 37, 2726-2739.

Toffoli, A., Onorato, M. \& Monbaliu, J. 2006 Wave statistics in unimodal and bimodal seas from a second-order model. Eur. J. Mech. (B/Fluids) 25 (5), 649-661.

Tulin, M. P. 1996 Breaking of ocean waves and downshifting. In Waves and Nonlinear Processes in Hydrodynamics. Fluid Mechanics and Its Applications, vol. 34. Springer.

Walker, D. A. G., TAYlor, P. H. \& EATOCK TAYlor, R. 2004 The shape of large surface waves on the open sea and the Draupner New Year wave. App. Ocean Res. 26, 73-83.

Waseda, T., Kinoshita, T. \& TAMURA, H. 2009 Interplay of resonant and quasi-resonant interaction of the directional ocean waves. J. Phys. Oceanogr. 39, 2351-2362.

WU, C. H. \& YAO, A. 2004 Laboratory measurements of limiting freak waves on currents. J. Geophys. Res. 109, C12.

YAN, S. \& MA, Q. W. 2010 QALE-FEM for modelling 3D overturning waves. Intl J. Numer. Meth. Fluids 63, 743-768.

YAO, A. \& WU, C. H. 2006 Spatial and temporal characteristics of transient extreme wave profiles on depth-varying currents. J. Engng Mech. 132, 1015-1025.

Zeff, B. W., Kleber, B., Fineberg, J. \& Lathrop, D. P. 2000 Singularity dynamics in curvature collapse and jet eruption on a fluid surface. Nature 403, 401-404.

Zhao, W., Wolgamot, H. A., Taylor, P. H. \& Eatock Taylor, R. 2017 Gap resonance and higher harmonics driven by focused transient wave groups. J. Fluid Mech. 812, 905-939. 